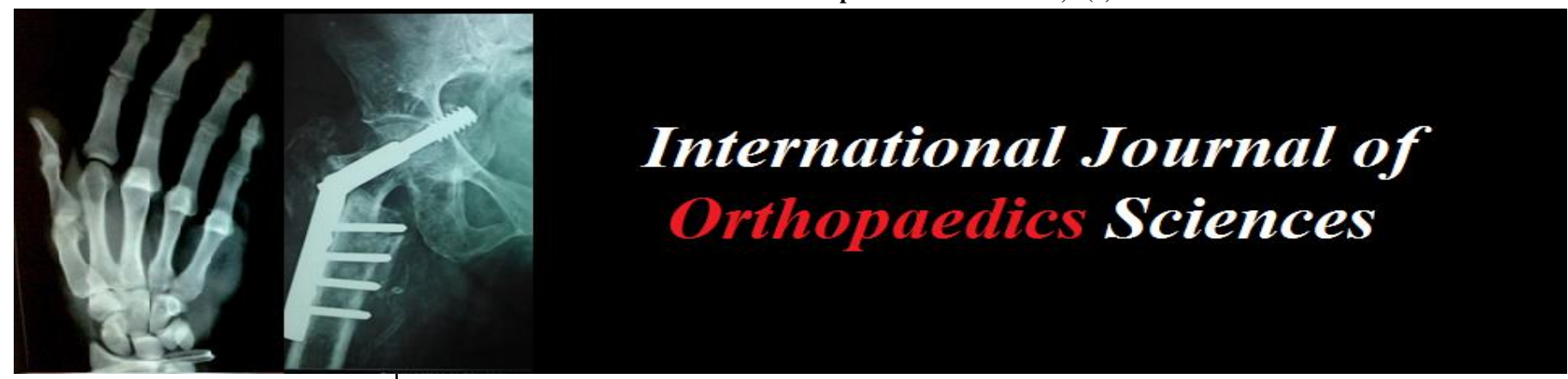

E-ISSN: 2395-1958

P-ISSN: 2706-6630

IJOS 2020; 6(4): 173-177

(C) $2020 \mathrm{IJOS}$

www.orthopaper.com

Received: 22-07-2020

Accepted: 26-08-2020

Dr. Anish Isapure

Isapure Orthopaedic Hospital,

Miraj, Maharashtra, India

Dr. William Isapure

Isapure Orthopaedic Hospital,

Miraj, Maharashtra, India

Dr. Sandeep Eden

Isapure Orthopaedic Hospital,

Miraj, Maharashtra, India

\section{Efficacy of core decompression with bisphosphonates and Prolotherapy compared with core decompression alone and core decompression with bisphosphonates in the management of avascular necrosis of hip joint}

\author{
Dr. Anish Isapure, Dr. William Isapure and Dr. Sandeep Eden
}

DOI: https://doi.org/10.22271/ortho.2020.v6.i4c.2338

\begin{abstract}
Background: Avascular necrosis (AVN) of hip joint or femoral head is complex disease with complete collapse of the femoral head. Core decompression is the mainstay treatment for grade I and II AVN of hip joint but the results were controversial. In this backdrop, the present study was undertaken to evaluate the combination of core decompression with bisphosphonates and prolotherapy in the treatment of AVN of hip joint.

Methods: 36 patients who were diagnosed with for grade I and II AVN of hip joint were recruited and they were divided into three groups $(n=12)$. The patients in three groups were treated with core decompression alone, core decompression with bisphosphonates and core decompression with bisphosphonates, prolotherapy. The patients were followed at $6^{\text {th }}$ month, after 1 year and 2 years respectively. Their outcomes and range of motion were recorded at each follow-up.

Results: The outcome of the study shows that the combined treatment of core decompression with bisphosphonates, prolotherapy showed fair outcome at the end of 2 year follow up with effective pain reduction during walking, squatting and cross leg. Meanwhile, core decompression alone and core decompression with bisphosphonates showed poor and good outcome.

Conclusion: Thus in patients with grade I and II AVN of hip joint combination of core decompression with bisphosphonates, prolotherapy would be effective in prevention of collapse and pain reduction.
\end{abstract}

Keywords: Avascular necrosis, hip joint, core decompression, bisphosphonates, prolotherapy

\section{Introduction}

Avascular necrosis (AVN) is termed as cell death of bone structures due to blockade of blood supply, which leads to collapse of bone components, destruction of bones and loss of joint function (Mont and Hungerford, 2006) ${ }^{[1]}$. AVN of the hip is a clinical condition due to restriction of blood supply to subchondral region of femur head leading to apoptosis of osteoblasts and osteocytes. It can be posttraumatic, alcohol or steroid induced and idiopathic variety (Koo et al., 2001) ${ }^{[2]}$. Management of AVN of hip joint depends on the severity or stage of the disease and the extent of the involvement. In the case of advanced stage (Stage IV), where the femoral head and acetabulum are damaged the only option is the total hip joint replacement we have no choice but total joint replacement or freezing the joint (Gangji et al., 2004) ${ }^{[3]}$. However, high challenges exist among the orthopedicians for the treatment of stage I and II AVN. The progression of disease can be stopped by simple management techniques such as simple drilling and bone graft implantation like cancellous or cortical like fibula (Chen et al., 2000) ${ }^{[4]}$. Further, treatment of AVN of hip joint is based on the two criteria, precollapsed or early collapsed stage and advanced collapse stage of hip joint. Mounting nonoperative treatment modalities and hip preserving surgical procedures have been reported for precollapsed and early collapsed stage of AVN of hip joint. Core decompression is the mainstay surgical technique for the management of stage 1 or stage $2 \mathrm{AVN}$ of femoral head. It reduces the intraosseous pressure in the femoral head and elevates the blood flow to the necrotic site, thus aiding the neobone formation (Bozic et al., 1999) ${ }^{[16]}$.
Corresponding Author: Dr. Anish Isapure Isapure Orthopaedic Hospital, Miraj, Maharashtra, India 
It is the cost effective surgical technique and the success of the treatment is mainly rely on etiology and radiographic variable such as size, location and collapse of lesion such as lesion size, location or collapse of the lesion (Ficat and Arlet, 1980) ${ }^{[18]}$

The pharmacological management includes the use of bisphosphonates for the prevention of early collapse in AVN of hip joint and in advances stages to extend the requirement of total hip replacement surgery (Agarwala et al., 2005) ${ }^{[20] .}$ Alendronate, a bisphosphonate act upon by restricting osteoclastic activity in the necrotic site and this increases the bone healing (Wang et al., 2008) ${ }^{[8]}$. However its major risk is the development of jaw osteonecrosis during the therapy (Schaudinn et al., 2012) ${ }^{[9]}$.

Prolotherapy or hypertonic dextrose injection is an injectionbased method for the treatment of wide range of chronic musculoskeletal pain conditions such as osteoarthritis (Rabago et al., 2005) ${ }^{[10]}$. Recent case report showed that prolotherapy was effective in the management of AVN of femoral head (Ozen and Baser, 2019) ${ }^{[11]}$.

In this backdrop, the present study was undertaken to evaluate the outcome of core decompression with bisphosphate and prolotherapy for the management of grade I - II of AVN of Hip joint.

\section{Patients and Methods}

In this comparative study 36 patients attending the Department of orthopedics, ---------- Hospital, diagnosed with stage I-II were selected.

\section{Inclusion criteria}

All cases of AVN femoral head upto grade I- II admitted in ------- hospital.

\section{Exclusion criteria}

Exclusion criteria were patient with sickle cell disease; patient having AVN of femoral; head grade III and grade IV; patient not willing for admission or operation; patient not giving written consent for the study.

\section{History and clinical examination}

All the patients in our study were first examined in the outpatient department. Patient demographic detail and the detailed information such as duration of symptoms, progression of symptoms, deformity, support required to walk or not, any history of trauma and history of other joint pain were collected. History of risk factors like steroids and alcoholism was also noted. Local as well as systemic examination (CNS, Cardiorespiratory and GI) was done to rule out any other associated disorder or multiple joint involvements or any other bony abnormalities.

\section{Investigations}

Hip: X-ray of both joint was taken in AP view and Lateral view or Frog views. MRI pelvis with both hips after establishing the diagnosis and staging of AVN and to evaluate the necrotic area of femur head

The preoperative medical evaluation of patients was necessary to judge patient's capability to withstand anesthesia and perioperative blood loss. Routinely chest X-ray, ECG, CBC and ESR, HIV, HBsAG, LFT, RFT, RBS, 2-D echocardiograpy were done.

\section{Grouping of Patients}

In this study based on the treatment methods the patients were divided into three groups as follows and each group contains 12 subjects $(\mathrm{n}=12)$,

Group 1: Patients treated with Core decompression alone

Group 2: Patient treated with Core decompression and Bisphosphonate

Group 3: Patient treated with Core decompression, Bisphosphonate and prolotherapy.

\section{Core decompression}

After obtaining the informed consent from the patient, the operative procedures were performed. Following spinal anaesthesia, patient was placed at lateral position on a operation table. The patient was subjected to panting and draping under aseptic conditions.

Then a $5 \mathrm{~cm}$ skin incision made at trochanteric ridge distally and subcutaneous tissue was cut in the same plane. After splitting tensor fascia latta and vastus lateralis, the bone was exposed and a guide pin was inserted from lateral femoral cortex $3 \mathrm{~cm}$ below the trochanteric ridge under IITV guidance. Then the guide pin was positioned towards the necrotic area centre in the femoral head and its placement was confirmed under IIT, an anterosuperior portion. Further, the core was created with $10 \mathrm{~mm}$ hollow meal. Scrapping was done using scoop to clear the dead necrotic bones using IITV. Then the void was filled with cancellous bone grafts which were isolated from the posterior iliac crest. Adequate filling was confirmed in IITV and layer wise closure was done.

\section{Core decompression and Bisphosphonate}

After the core decompression, patients were instructed to take the prescribed regimen of $35 \mathrm{mg}$ of Actonel (Sanofi India Limited) taken orally once a week. Actonel was prescribed for a period of 1 year and followed up regularly.

\section{Core decompression, Bisphosphonate and prolotherapy}

Followed by core decompression and bisphosphonate the prolotherapy was initiated by injecting $5 \mathrm{ml}$ of $25 \%$ dextrose with $1 \mathrm{ml}$ lignocaine $2 \%$.

\section{Follow up}

The patients were followed up for 6 months, 1 year and 2 years for the symptoms of pain during walking, squatting and cross leg were evaluated. Further range of motion was also evaluated during the follow up period.

\section{Results}

In the present study the mean age of the patients was found to be $51.57 \pm 8.24$ years. Out of 36 patients 26 were males and 10 were females. Among the 36 patients, 20 cases were presented with grade II AVN of femur head and 16 cases showed grade I AVN of femur head.

Table 1 shows the outcome of Core decompression alone in the management of AVN of hip joint. During treatment with core decompression the results were satisfactory after 6 months, unsatisfactory after 1 year and poor after follow up of 2 years. The symptoms of pain during walking, squatting and cross leg were present at 6 months and 1year follow up. 
Table 1: Outcome of Core decompression alone in AVN of Hip joint treatment

\begin{tabular}{|c|c|c|c|}
\hline Symptoms & Result & Follow Up & Range of motion \\
\hline $\begin{array}{c}\text { Pain during } \\
\text { walking and squatting cross leg }\end{array}$ & Fair & $\begin{array}{c}\text { After 6 } \\
\text { months }\end{array}$ & Flexion and extension of Hip joint. No shortening \\
\hline $\begin{array}{c}\text { Pain during walking and squatting } \\
\text { cross leg }\end{array}$ & Unsatisfactory & After 1 years & $\begin{array}{c}\text { Restriction of movement Flexion, Extension and Circumduction with 1 cm } \\
\text { shortening }\end{array}$ \\
\hline All movements restriction & Poor & After 2 years & Shortening \\
\hline
\end{tabular}

Table 2 shows the combination of core decompression and bisphosphonate in the management of AVN of hip joint. During treatment with core decompression and bisphosphonate results were fair after 6 months, good after 1 year and 2 years of follow up. The symptoms of pain during walking, squatting and cross leg were decreased effectively during the follow up of 6 months, 1 year and 2 years.

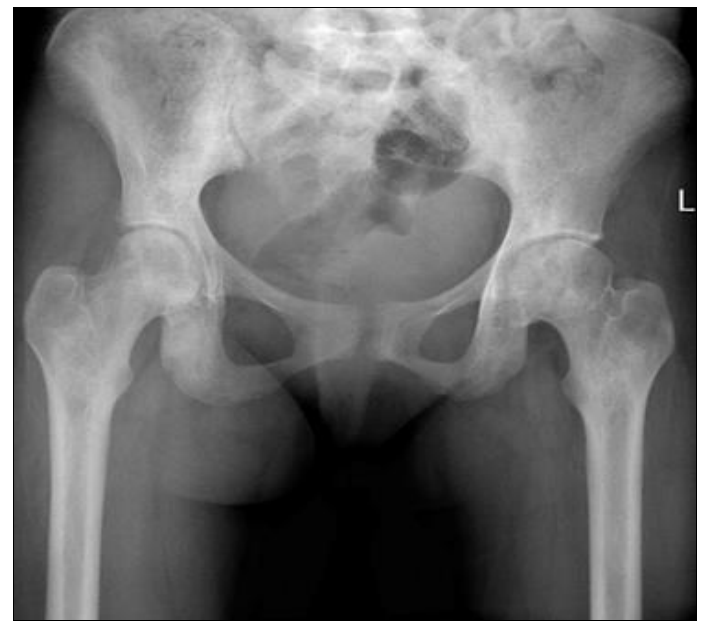

Fig 1: Pre- op

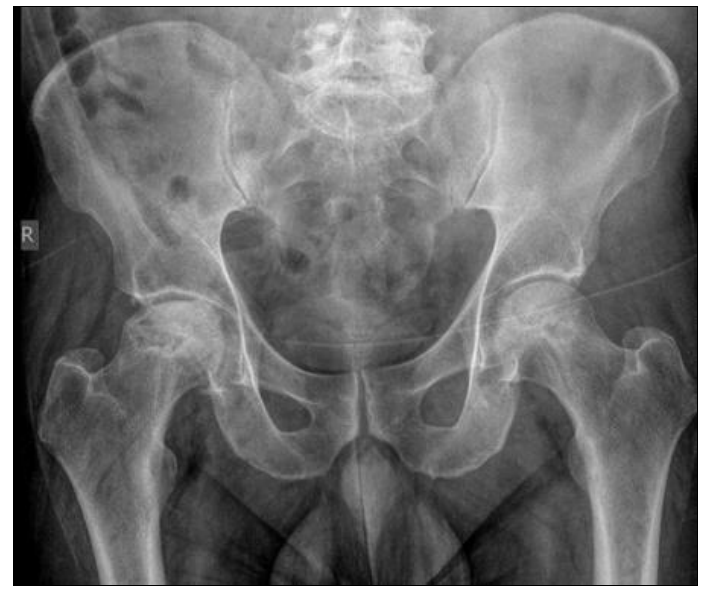

Fig 2: Follow up (After 2 years)

Table 2: Outcome of Core decompression with bisphosphonate in AVN of Hip joint treatment

\begin{tabular}{|c|c|c|c|}
\hline Symptoms & Result & Follow Up & Range of Motion \\
\hline $\begin{array}{c}\text { Pain during walking and } \\
\text { squatting, cross leg }\end{array}$ & Fair & $\begin{array}{c}\text { After 6 } \\
\text { Months }\end{array}$ & $\begin{array}{c}\text { Flexion }-70^{\circ} \\
\text { Extension }-20^{\circ} \\
\text { Circumduction } \\
\text { Terminal Pain }\end{array}$ \\
\hline $\begin{array}{c}\text { Pain during walking and } \\
\text { squatting, cross leg }\end{array}$ & Fair & After 1 year & $\begin{array}{c}\text { Flexion }-80^{\circ} \\
\text { Extension -20 } \\
\text { Circumduction } \\
\text { Terminal Painful }\end{array}$ \\
\hline All Movements restriction & Fair & $\begin{array}{c}\text { After 2 } \\
\text { years }\end{array}$ & Improved free \\
\hline
\end{tabular}

Table 3 shows the combined core decompression, bisphosphonate and prolotherapy for the management of AVN of Hip joint. During treatment with core decompression, bisphosphonate and prolotherapy the results were good after 6 months, good after 1 year and fair after 2 years of follow up. The symptoms of pain during walking, squatting and cross leg were decreased effectively during the follow up of 6 months, 1 year and 2 years

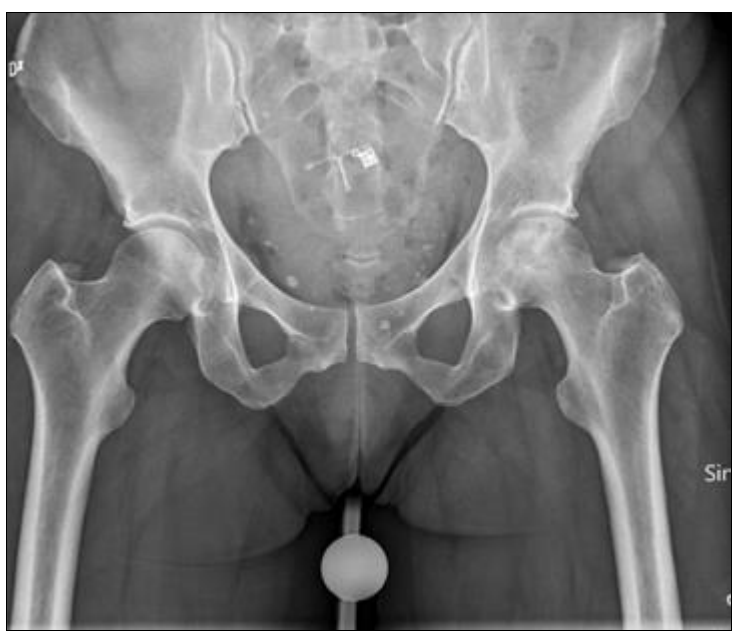

Fig 3: Pre-operative X-Ray

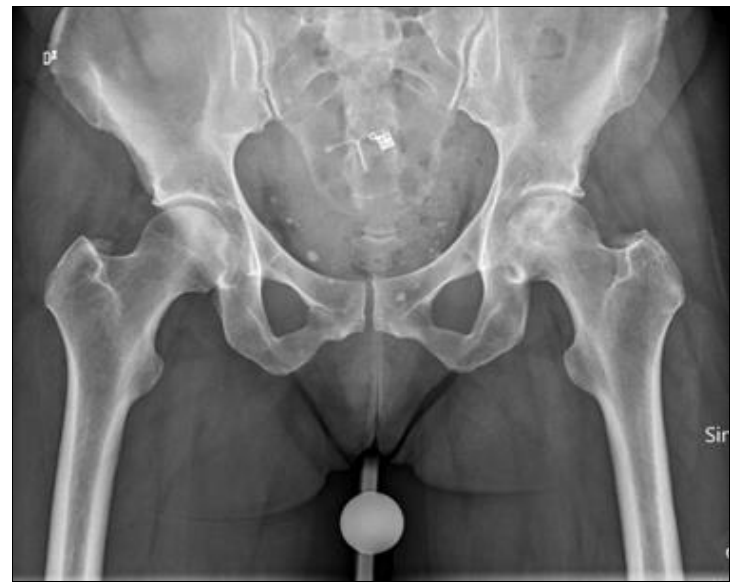

Fig 4: 2 year Follow up

Table 3: Outcome of Core decompression, bisphosphonate and prolotherapy AVN of Hip joint treatment

\begin{tabular}{|c|l|l|c|}
\hline Symptoms & Result Follow Up & Range of Motion \\
\hline $\begin{array}{c}\text { Pain during walking and } \\
\text { squatting, cross leg }\end{array}$ & Good & $\begin{array}{c}\text { After 6 } \\
\text { Months }\end{array}$ & $\begin{array}{c}\text { Flexion }-80^{\circ} \\
\text { Extension }-20^{\circ} \\
\text { Circumduction } \\
\text { Pain free }\end{array}$ \\
\hline $\begin{array}{c}\text { Pain during walking and } \\
\text { squatting, cross leg }\end{array}$ & Good & $\begin{array}{c}\text { After 1 } \\
\text { Years }\end{array}$ & $\begin{array}{c}\text { Improving slowly } \\
\text { Hip-Joint }\end{array}$ \\
\hline All Movements restriction & Good & After 2 & $\begin{array}{c}\text { Shortening Erosion of } \\
\text { Yead of tenus } \\
\text { Yo shortening }\end{array}$ \\
\hline
\end{tabular}




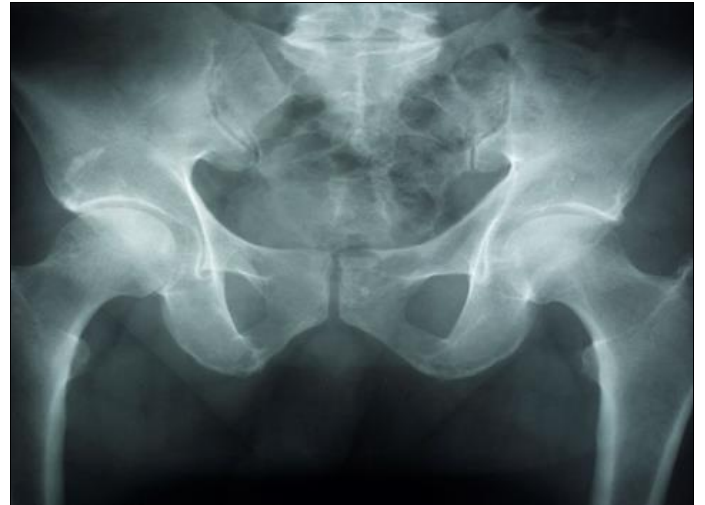

Fig 5: Pre-operative x-ray

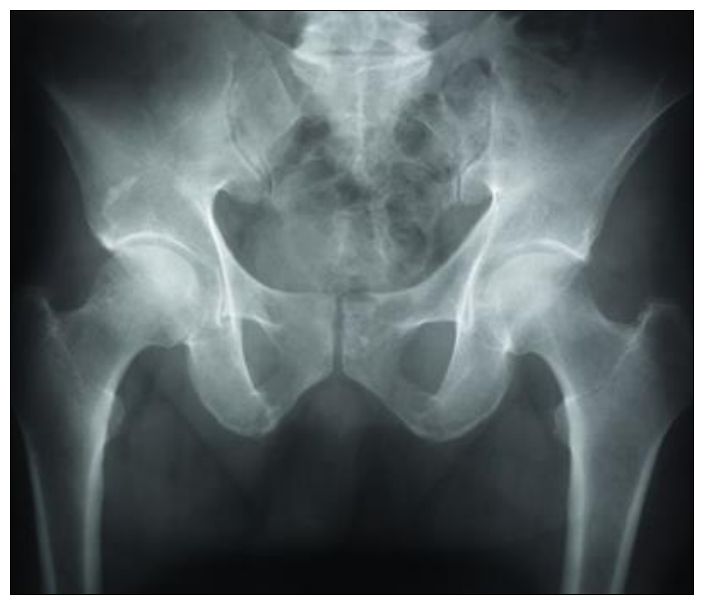

Fig 6: Xray after 2year Follow-up

\section{Discussion}

Avascular necrosis (AVN) of the femoral head or hip joint is as a result of obstructed blood flow to femoral head primarily due to intravascular coagulation of the intraosseous microcirculation. This leads to inadequate perfusion and causes bone necrosis, microfracture, and collapse of articular surface in advanced stages (Shah et al., 2015) ${ }^{[12]}$. Mounting treatment strategies have been proposed for the AVN of femoral head or hip joint. Nonsurgical treatments encompass pharmacologic therapies, such as hypolipidemic agents, anticoagulants, vasoactive substances, and bisphosphonates. Non pharmacological strategies include extracorporeal shockwave therapy, pulse electromagnetic therapy, and hyperbaric oxygen therapy (Moya-Angeler et al., 2015) ${ }^{[13]}$. Surgical options range from core decompression to total hip arthroplasty (Mont et al., 2015) ${ }^{[14]}$. So in our study we have done the comparative evaluation of core decompression alone, core decompression and bisphosphonates and core decompression, bisphosphonates and prolotherapy for the management of grade I-II AVN of femoral head or hip joint.

In this study patients undergone core decompression displayed unsatisfactory and poor outcome after 1 year and 2 years follow-up. Further there was no effective pain reduction and restriction in movement flexion, extension and circumduction after treatment with core decompression. Our results were in agreement with the previous study conducted by Gangji et al. in which after 60 months of follow up eight of the eleven hips in the patients undergone core decompression had deteriorated to the fractural stage (Gangji et al., 2011) ${ }^{[15]}$. Albiet, previous studies reports that core decompression is effective in earlier stages of the disease, evidence of its efficacy in preventing collapse has been controversial with the overall rate of success varying from as low as $40 \%$ to as high as 89\% (Bozic et al., 1999; Colwell et al., 1996; Ficat and Arlet, 1980) ${ }^{[16,17,18]}$.

Bisphosphonate therapy restores the structural bone weakening mediated by reparative osteocytic necrosis and apoptosis through its anti-resorptive and anti-inflammatory actions (Wang et al., 2014) ${ }^{[19]}$. Bisphosphonates act by blocking the osteoclasts activity, thus increasing the bone resorption. Recent studies have showed that bisphosphonate treatment reduces the patient disability scores and also reduced the collapse rate AVN patients (Agarwala et al., 2005; Lai et al., 2005) ${ }^{[20]}$. Lai et al. showed that in 2 year follow up period, only two of the 25 hips in the bisphosphonate group had loss of femoral head integrity compared with 19 of the 25 hips in the control group (Lai et al., 2005) [21]. In our study patients treated with core decompression and bisphosphonate showed good results after 2 years of follow up. Further the pain during walking, squatting and cross leg were effectively reduced as compared to the patients treated with core decompression alone. Further study by Kang et al. showed an $83.6 \%$ overall success rate after treatment with core decompression and bisphosphonate and reported a mean onset of progression of collapse at 23 months post-operatively (Kang et al., 2012) ${ }^{[22]}$.

Further, in our study we have evaluated the combination of core decompression, bisphosphonate and prolotherapy for the management of AVN of femoral head. Till date no clinical studies have evaluated this combined treatment and only a recent study had evaluated the efficacy of prolotherapy alone in the management of AVN of femoral head (Ozen and Baser, 2019) ${ }^{[11]}$. Prolotherapy is an injection based therapy for the treatment of chronic musculoskeletal injury, including knee osteoarthritis (Rabago et al., 2010) ${ }^{[23]}$. The basic principle of prolotherapy is injection of minimal volume of irritant solution at various pain sites and also at joint spaces for several treatment sessions (Rabago et al., 2010) [23]. Hypertonic dextrose is generally used for prolotherapy and it stimulates the healing of chronically injured extra- and intraarticular tissue by releasing the growth factors (Reeves and Hassanein, 2000) ${ }^{[24]}$. In our study treatment with combination of core decompression, bisphosphonate and prolotherapy displayed fair results after two years of follow up as compared to core decompression alone and core decompression with bisphosphonate.

\section{Conclusion}

In the present study patients treated with core decompression alone showed poor outcome, whilst core decompression and bisphosphonate therapy showed good outcome. However, combination of core decompression, bisphosphonate and prolotherapy displayed fair results in our study. Thus in patients with grade I and II AVN of hip joint combination of above strategy are highly recommended. However future studies with large sample size and long term follow-up of 5 years are highly warranted.

\section{References}

1. Mont MA, Hungenford DS. Non traumatic osteonecrosis of the femoral head: ten year later-current consepts review.J Bone Joint Surg Am 2006;88:1107-29.

2. Koo SH, Song HR, Yang JW, Yang P, Kim JR, Kim YM. Trochanteric rotational osteotomy for osteonecrosis of femoral head. J Bone Joint Surg 2001;83B:83-9.

3. Gangji V, Hauzeur JP, Matos C, De Maertelaer V, Toungouz M, Lambermont M. Treatment of osteonecrosis of the femoral head with implantation of 
autologous bone-marrow cells. A pilot study. J Bone Joint Surg Am 2004;86(6):1153-60.

4. Chen CH, Chang JK, Huang KY, Hung SH, Lin GT, Lin SY. Core decompression for osteonecrosis of the femoral head at pre-collapse stage. Kaohsiung J Med Sci 2000;16:76-82

5. Bozic KJ, Zurakowski D, Thornhill TS. Survivorship analysis of hips treated with core decompression for nontraumatic osteonecrosis of the femoral head. J Bone Joint Surg Am 1999;81(2):200-9.

6. Ficat RP, Arlet J. Ischemia and Necroses of Bone. In: Hungerford DS, editor. Baltimore: Williams and Wilkins 1980.

7. Agarwala S, Jain D, Joshi VR, Sule A. Efficacy of alendronate, a bisphosphonate, in the treatment of AVN of the hip. A prospective open-label study. Rheumatology (Oxford) 2005;44:352-9.

8. Wang CJ, Wang FS, Yang KD, Huang CC, Lee MS, Chan YS et al. Treatment of osteonecrosis of the hip: Comparison of extracorporeal shockwave with shockwave and alendronate. Arch Orthop Trauma Surg 2008;128:901-8.

9. Schaudinn C, Gorur A, Webster P, et al: Quantification by energy dispersive X-ray spectroscopy of alendronate in the diseased jaw bone of patients with bisphosphonaterelated jaw osteonecrosis. Oral Surg Oral Med Oral Pathol Oral Radiol 2012114:480-486.

10. Rabago D, Best TM, Beamsley M, Patterson J. A systematic review of prolotherapy for chronic musculoskeletal pain. Clin J Sport Med 2005;15(5):37680 .

11. Ozen B, Baser M.Is Prolotherapy Effective in the Treatment of Avascular Necrosis of the Femoral Head? Altern Ther Health Med 2019;25(5):57-59.

12. Shah KN, Racine J, Jones LC, Aaron RK. Pathophysiology and risk factors for osteonecrosis. Curr Rev Musculoskelet Med 2015;8(3):201-9.

13. Moya-Angeler J, Gianakos AL, Villa JC, Ni A, Lane JM. Current concepts on osteonecrosis of the femoral head. World J Orthop 2015;6(8):590-601.

14. Mont MA, Cherian JJ, Sierra RJ, Jones LC, Lieberman JR. Nontraumatic Osteonecrosis of the Femoral Head: Where Do We Stand Today? A Ten-Year Update. J Bone Joint Surg Am 2015;97(19):1604-27.

15. Gangji V, De Maertelaer V, Hauzeur JP. Autologous bone marrow cell implantation in the treatment of nontraumatic osteonecrosis of the femoral head: Five year follow-up of a prospective controlled study. Bone 2011;49:1005-9.

16. Bozic KJ, Zurakowski D, Thornhill TS Survivorship analysis of hips treated with core decompression for nontraumatic osteonecrosis of the femoral head. J Bone Joint Surg Am 1999;81(2):200-9.

17. Colwell CW Jr, Robinson CA, Stevenson DD, Vint VC, Morris BA. Osteonecrosis of the femoral head in patients with inflammatory arthritis or asthma receiving corticosteroid therapy. Orthopedics 1996;19(11):941-6.

18. Ficat R, Arlet J. Ischemia and necrosis of bone. Baltimore: Williams \& Wilkins; Necrosis of the femoral head 1980,171-182.

19. Wang C, Peng J, Lu S. Summary of the various treatments for osteonecrosis of the femoral head by mechanism: A review. Exp Ther Med 2014;8(3):700-706.

20. Agarwala S, Jain D, Joshi VR, Sule A. Efficacy of alendronate, a bisphosphonate, in the treatment of AVN of the hip. A prospective open-label study. Rheumatology (Oxford) 2005;44(3):352-9.

21. Lai KA, Shen WJ, Yang CY, Shao CJ, Hsu JT, Lin RM. The use of alendronate to prevent early collapse of the femoral head in patients with nontraumatic osteonecrosis. A randomized clinical study. J Bone Joint Surg Am 2005;87(10):2155-9.

22. Kang P, Pei F, Shen B, Zhou Z, Yang J. Are the results of multiple drilling and alendronate for osteonecrosis of the femoral head better than those of multiple drilling? A pilot study. Joint Bone Spine 2012;79(1):67-72.

23. Rabago D, Slattengren A, Zgierska A. Prolotherapy in primary care practice. Prim Care 2010; 37(1):65-80.

24. Reeves KD, Hassanein K. Randomized prospective double-blind placebo-controlled study of dextrose prolotherapy for knee osteoarthritis with or without ACL laxity. Altern Ther Health Med 2000;6(2):68-74,77-80. 